\title{
BMJ Open A tailored strategy for designing the Walk-Copenhagen (WALK-Cph) intervention to increase mobility in hospitalised older medical patients: a protocol for the qualitative part of the WALK-Cph project
}

Jeanette Wassar Kirk, ${ }^{1}$ Ann Christine Bodilsen, ${ }^{1,2}$ Tine Tjørnhøj-Thomsen, ${ }^{3}$ Mette Merete Pedersen, ${ }^{4,5}$ Thomas Bandholm, ${ }^{4,5}$ Rasmus Skov Husted, ${ }^{4,5}$ Lise Kronborg Poulsen, ${ }^{1}$ Janne Petersen, ${ }^{1,6}$ Ove Andersen, ${ }^{1}$ Per Nilsen ${ }^{7}$

To cite: Kirk JW, Bodilsen AC, Tjørnhøj-Thomsen T, et al. A tailored strategy for designing the Walk-Copenhagen (WALK$\mathrm{Cph}$ ) intervention to increase mobility in hospitalised older medical patients: a protocol for the qualitative part of the WALK-Cph project. BMJ Open 2018;8:e020272. doi:10.1136/ bmjopen-2017-020272

- Prepublication history and additional material for this paper are available online. To view these files, please visit the journal online (http://dx.doi. org/10.1136/bmjopen-2017020272).

Received 24 October 2017 Revised 24 December 2017 Accepted 25 January 2018

Check for updates

For numbered affiliations see end of article.

Correspondence to Dr Jeanette Wassar Kirk; jeanette.wassar.kirk@regionh.dk

\section{ABSTRACT}

Introduction Older medical patients ( $>65$ years) represent $54 \%$ of the admissions to Danish medical and emergency departments. Acute admissions and bedrest during hospitalisation are independent risk factors for death and dependency in older patients. Even short hospitalisations are associated with increased dependency in activities of daily living after discharge. Interventions that increase mobility during hospitalisation are therefore important. The purpose of this protocol is to describe the intervention design of the WALK-Copenhagen project, aimed at increasing 24 hours mobility in older medical patients during acute hospitalisations and following discharge.

Methods and analysis This study is based on ethnographic fieldwork and interviews. Workshops are used to develop and co-design the intervention in collaboration with key stakeholders (patients, relatives, health professionals and researchers). The theory of cultural learning processes, and the cultural historical activity theory will be used to help us understand the interaction between health professionals, structures and objects in relation to mobility in the medical departments. Ethics and dissemination The project will adhere to the directives of the Helsinki Declaration. Ethical approval was not required for the study since formal ethical approval is not mandatory for studies that do not involve biomedical issues (I-Suite no: 05078) according to Danish law. Informed consent was obtained for all participants. The results will be disseminated to health professionals, managers, patients and relatives, who will be invited to afternoon meetings where the project will be discussed. The results will be published in peer-reviewed scientific journals and presented at scientific conferences.

\section{INTRODUCTION}

It has been known for a long time that complete bed-rest and low mobility in hospitalised patients can have serious health

\section{Strengths and limitation of this study}

- The external validity, that is, generalisability of study findings, may be compromised since the results cannot be directly transferred to hospital settings elsewhere.

- A strength of the study is the use of multidisciplinary teams, as it provides different perspectives on the multidimensional issue under study.

- A strength of the study is the use of theoretical frameworks as it enhances the ability to understand and explain how and why certain results are achieved.

consequences. ${ }^{1}$ Nonetheless, and for a number of different reasons, today's hospitalised patients are very immobile. ${ }^{2}$ In older medical patients (aged 65 years or more), acute admissions and bed-rest during hospitalisation are independent risk factors for death and dependency ${ }^{3}$ and even short hospitalisations are associated with increased dependency in activities of daily living after discharge. ${ }^{5}$ Hence, interventions to increase mobility in older patients during hospitalisation are greatly needed to avoid serious health consequences after hospitalisation, such as increased dependency.

Older people admitted acutely to hospital for medical reasons represent $54 \%$ of the annual admissions to Danish medical and emergency departments (EDs). ${ }^{6}$ These older medical patients demonstrate a very low level of mobility during hospitalisation. ${ }^{78} \mathrm{We}$ recently reported the degree of low mobility in these patients to amount to a median of 17 hours a day in bed and less than 1 hour 
of walking a day during hospitalisation. ${ }^{7}$ Making these numbers even more alarming is the fact that all patients walked independently (with or without walking aids) at admission. ${ }^{7}$ This low level of mobility during hospitalisation in older medical patients poses a high risk of self-reported functional decline. ${ }^{9}{ }^{10}$ Patients, who lose functional capacity during hospitalisation have reduced ability to recover the lost function. ${ }^{49}$ Accordingly, many older medical patients will experience sustained functional limitations after hospitalisation, placing them at increased risk of further functional decline, which can lead to dependency in activities of daily living, institutionalisation and death. ${ }^{10}{ }^{11}$ Interventions that improve mobility during hospitalisation are therefore important.

Despite great knowledge of the importance of increased mobility to counteract functional decline in older medical patients, is has proven to be difficult to achieve. ${ }^{2}$ The reported difficulties include: lack of space and staff, medical equipment restricting out of the bed mobility, lack of assistive devices and help from staff, lack of patient motivation, patient weakness and pain, and different views on the health professionals' roles concerning the task of mobilising patients. ${ }^{2} 1213$

Physiotherapists who work with older medical patients consider mobility to be a core task. ${ }^{13}$ However, the complexity of physiotherapy practice has increased due to changes in healthcare, for example, a high patient turnover which places higher demands on physiotherapists to ensure effective management of patients. ${ }^{14}$ Thus, time and temporality become determinants to continuously support mobility of older medical patients during hospitalisation. Hence, patient mobility is supported by nurses, who hold a key position in supporting mobility in older patients. However, nurses do not consider mobility as a part of their core tasks. ${ }^{15}$ Numerous determinants to nurses' and physicians' efforts to improve mobility in patients have been identified. ${ }^{2}$ These include concerns about mobility-related falls and doubts regarding the patients' motivation for mobility during acute illness. Thus, nurses and physicians do not encourage older medical patients to be mobilised. ${ }^{2}$ Based on different professional perspectives and priorities, there seems to be a paradox regarding older medical patients' mobility: physiotherapists perceive mobility as an important task to prevent functional decline, but nurses and other health professionals, who spend the most time with the patients, do not consider patient mobility a core task and tend to focus on medical procedures and patient flow. ${ }^{16} 17$ Hence, patient mobility is dependent on several factors such as the efforts and beliefs of more than one group of health professionals and also on complex factors such as patients' knowledge, motivation and attitudes.

To consider the determinants of mobility reviewed above-and to facilitate intervention uptake and clinical implementation-there is a need for developing an intervention that takes the multiple determinants of older patients' mobility into account. An intervention that is developed from a user perspective and is adapted to the local context is more likely to be successful. ${ }^{18}$ A growing body of evidence shows that patient engagement can yield better health outcomes, ${ }^{19}$ contribute to improvements in healthcare quality and patient safety, ${ }^{20}$ and lead to research findings that are more pertinent to the users' concerns and dilemmas. ${ }^{18}$ Nevertheless, user engagement is not common at the design phase of interventions. Instead, an intervention is typically designed on the basis of the literature, only rarely incorporating knowledge, skills and experiences from, for example, health professionals. ${ }^{21}$ The WALK -Copenhagen (WALK-Cph) intervention will be developed in collaboration between patients, relatives, researchers and health professionals. This collaboration makes it possible to use different experiences, skills, knowledge and expertise in the study while recognising that the participants' local knowledge improves the external validity of the intervention. We therefore believe that the WALK-Cph project can make valuable methodological contributions to intervention research.

Thus, the aim of this protocol paper is to describe the intervention design of WALK-Cph, which is a mixedmethods clinical project aimed at developing and implementing an intervention to increase mobility in older medical patients during acute hospitalisations and following discharge. The qualitative part of the study started in January 2017 and will end by 1 August 2018. The intervention design is based on a series of qualitative studies that are outlined in figure 1.

\section{METHODS AND ANALYSES \\ Philosophy of science}

WALK-Cph is inspired by a critical realistic approach that focuses on the search for generative mechanisms that explain the social world. Realism as a philosophy of science is situated between the extremes of positivism and relativism ${ }^{22}$ and acknowledges that the world is an open system with structures and layers that interact to form mechanisms and contexts. Thus, we are interested in: (1) identifying, analysing and understanding the social world of the health professionals regarding mobilisation of older medical patients and (2) the health professionals' responses to different resources offered within new interventions. The focus is on understanding how the interaction between visible and non-visible features forms the health practitioners' actions, reactions and way of thinking, both individually and collectively. ${ }^{23}$

In a critical realistic view, the world, that is, in this study the medical departments, is divided into three domains: (1) the empirical domain (events and phenomena that can be perceived objectively); (2) the actual domain (events and phenomena that take place regardless of whether they can be perceived or not, but which are affecting the empirical domain); and (3) the real domain (structures and generative mechanisms, eg, power, political decisions and relationships). Thus, 


\begin{tabular}{|c|c|c|c|c|c|c|}
\hline & \multicolumn{2}{|c|}{$\begin{array}{c}\text { Phase 1: } \\
\text { Design }\end{array}$} & \multicolumn{2}{|c|}{$\begin{array}{c}\text { Phase 2: } \\
\text { Fidelity }\end{array}$} & \multirow{2}{*}{$\begin{array}{c}\text { Phase 3: } \\
\text { Intervention } \\
\begin{array}{c}\text { Effect of intervention } \\
\text { (Study } 3 \mathrm{a} \text { ) }\end{array}\end{array}$} & \multirow[t]{2}{*}{$\begin{array}{l}\text { Phase 4: } \\
\text { Adoption }\end{array}$} \\
\hline & $\begin{array}{l}\text { Collaborative design } \\
\text { of intervention } \\
\text { (Study la) }\end{array}$ & & $\begin{array}{c}\text { Fidelity of } \\
\text { intervention } \\
\text { (Study 2a) }\end{array}$ & $\begin{array}{c}\text { Redesign of } \\
\text { intervention } \\
\text { (Study 2c) }\end{array}$ & & \\
\hline 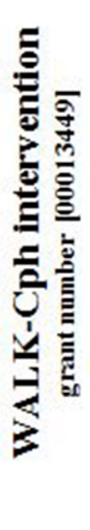 & $\begin{array}{c}\text { Practice observation } \\
\text { study: } \\
\text { Observations of } \\
\text { everyday practice to } \\
\text { understand the context } \\
\text { Intervention design } \\
\text { study: } \\
\text { Workshops I+I-III with } \\
\text { users and researchers to } \\
\text { design the intervention } \\
\text { Interrention } \\
\text { determinant study: } \\
\text { Focus group interviews } \\
\text { to identify barriers and } \\
\text { facilitators for the } \\
\text { planned intervention }\end{array}$ & & $\begin{array}{l}\text { Observational study } \\
\text { to measure fidelity } \\
\text { of the intervention }\end{array}$ & $\begin{array}{l}\text { Workshop IV with } \\
\text { users and } \\
\text { researchers for } \\
\text { further } \\
\text { development and } \\
\text { refimement of the } \\
\text { intervention }\end{array}$ & $\begin{array}{c}\text { Randomized } \\
\text { Controlled Trial: } \\
\text { To measure effect of the } \\
\text { invention } \\
\text { Fidelity of intervention: } \\
\text { Observations to assess } \\
\text { delivery of intervention }\end{array}$ & \\
\hline \multirow{2}{*}{ 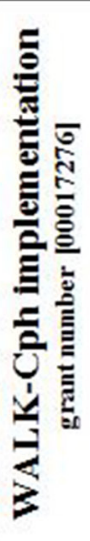 } & & $\begin{array}{l}\text { Design and } \\
\text { development of } \\
\text { implementation } \\
\text { strategy to support } \\
\text { the intervention } \\
\text { (Study lb) }\end{array}$ & $\begin{array}{c}\text { Fidelity of } \\
\text { implementation } \\
\text { strategies } \\
\text { (Study 2b) }\end{array}$ & $\begin{array}{c}\text { Redesign of } \\
\text { implementation } \\
\text { strategies } \\
\text { (Study 2d) }\end{array}$ & $\begin{array}{c}\text { Fidelity of } \\
\text { implementation } \\
\text { strategies } \\
\text { (Study } 3 \text { b) }\end{array}$ & $\begin{array}{l}\text { Adoption study } \\
\quad \text { (Study 4) }\end{array}$ \\
\hline & & $\begin{array}{l}\text { Implementation strategy } \\
\text { design study: } \\
\text { Workshop with users } \\
\text { (managers and key } \\
\text { implementation staff) and } \\
\text { researchers to identify } \\
\text { select and monitor } \\
\text { relevant implementation } \\
\text { strategies. }\end{array}$ & $\begin{array}{l}\text { Observational study } \\
\text { to measure fidelity } \\
\text { of implementation } \\
\text { strategies. }\end{array}$ & $\begin{array}{l}\text { Workshop with } \\
\text { users (managers } \\
\text { and key } \\
\text { implementation } \\
\text { staff) and } \\
\text { researchers to re- } \\
\text { design and monitor } \\
\text { relevant } \\
\text { implementation } \\
\text { strategies based on } \\
\text { the fidelity study } \\
\text { and workshops. }\end{array}$ & $\begin{array}{l}\text { (im case of redesign } \\
\text { following } 2 \mathrm{~d} \text { ) } \\
\text { Observational study to } \\
\text { measure fidelity }\end{array}$ & $\begin{array}{l}\text { Observations of } \\
\text { everyday practice and } \\
\text { comparison with mitial } \\
\text { observations and semi- } \\
\text { structured interviews. }\end{array}$ \\
\hline
\end{tabular}

Figure 1 The WALK -Copenhagen (WALK-Cph) intervention and implementation activities (contents covered by the present protocol are in red).

reality is layered like an iceberg extending beneath the surface where it is not visible to the eye. In a critical realistic approach, the science is about exploring the third domain, the real domain. It is about going from experiencing a phenomenon and what is immediately perceived, to understanding and explaining which structures and mechanisms create the phenomenon. ${ }^{22}$

Adopting a critical realism position will allow us to focus on the interaction between actors and structures over time. A realistic methodology consists of different phases. The first phase will be to clarify what constitutes mobility of older medical patients. Second, empirical data on the phenomenon, that is, mobility (movement sensor data and data from field study and barrier screening), will be collected. The third step will be to create new concepts, hypotheses, models or theories about mobility (abduction). This preliminary new knowledge will be presented in workshops for the health professionals and other researchers as a verification process. If the workshop participants can associate with the new concepts, models or hypotheses, a sound basis for the new knowledge to be used in practice has been created. ${ }^{24}$

\section{Mobility}

In WALK-Cph, mobility is defined in accordance with Satarino et $a l,{ }^{25}$ who state that mobility refers to 'Movement in all of its forms, including basic ambulation, transferring from a bed to a chair, walking for leisure and the completion of daily tasks, engaging in activities associated with work and play, exercising, driving a car and using various forms of public transport'. ${ }^{25}$ In addition, our definition of mobility includes mobilisation, as many activities in and around patients in a medical department also relate to passive transferring. Therefore, in WALK-Cph mobility refers to situations where the individual is actively involved in movement and situations where the individual is passively moved, for example, moved around in the bed.

\section{Study design}

WALK-Cph is a pragmatic cross-sectoral and mixedmethods project with the overall aim of increasing 
24 hours mobility in older patients during acute hospitalisation and following discharge. The primary outcome for the WALK-Cph study is increased mobility and will be estimated as steps, transitions or upright time, based on thigh-worn accelerometry using activPAL3 activity monitors (PAL Technologies, Glasgow, UK). Whether the primary outcome will be expressed as steps, transitions or upright time depends on the initial pilot and fidelity testing of the intervention, the outcomes and other trial procedures (study 2a and 2c, figure 1) to help qualify the randomised controlled trial (study $3 a$, figure 1) of the WALK-Cph project. The intervention is based on an assumption that by tailoring the intervention to the local context the likelihood of a successful implementation will increase. ${ }^{1826}$ This will be done by developing and co-designing the intervention in collaboration with key stakeholders such as patients, relatives, health professionals and researchers, in accordance with the BMJ campaign 'Partnering with patients' (http:// www.bmj.com/company/qip_examples/partneringwith-patients/). A tailored intervention is defined as an intervention in which the identification of barriers has been undertaken before the design and delivery of the intervention. ${ }^{18}$

The design of the intervention was inspired by the Medical Research Council framework for the development and evaluation of complex interventions to improve health. ${ }^{21}$ However, instead of first conducting an intervention study to ascertain clinical effectiveness and then considering implementation, WALK-Cph is designed both as an intervention and an implementation study, a so-called hybrid design. ${ }^{27}$ This means that the implementation study is planned from the outset of the project. Hybrid design has been advocated to improve the speed of generating new knowledge and to increase the benefit and uptake of clinical research. ${ }^{27}$

In four studies, we will design (phase I), fidelity-test (phase II), impact-test (phase III) and measure adoption (phase IV) of the intervention (figure 1). Following an initial observational study, the health professionals from two intervention departments will be asked to participate in workshops and individual interviews during the full study period (figure 1).

In order to achieve the overall project aim, the following research questions will be addressed in the qualitative studies of WALK-Cph:

1. Which cultural practices exist for mobility of older medical patients in the medical departments?

2. What are the roles of different professional cultures both regarding mobility of older patients and regarding collaboration between different professional groups to achieve increased mobility in older patients during and after hospitalisation?

3. How can we develop a patient intervention that is tailored to local cultural practices and based on a high degree of user engagement by health professionals, patients and their relatives?
4. How does a tailored patient intervention influence the extent to which health professionals and patients adhere to recommendations for managing increased mobility in older patients during and after hospitalisation?

\section{Study setting}

WALK-Cph will be carried out in Denmark where the healthcare system is publicly funded by the taxpayers. The Danish welfare state provides free treatment for primary medical care, hospitals and home-based care services for all citizens. WALK-Cph will be conducted at six medical departments in three public hospitals in the capital region of Copenhagen, Denmark. In addition, physiotherapy departments, a municipality and a municipality-based rehabilitation centre will participate.

WALK-Cph will use a purposeful sampling approach ${ }^{28}$ to reflect the diversity in medical specialties and to obtain rich information concerning the mobility practice in medical patients. We will select departments that reflect many facets of the medical specialty rather than focusing on one specialty. Based on this, we will include medical departments where older medical patients are admitted and where increased mobility is expected to be one of the core tasks of care and treatment. Six different departments will be chosen to participate: (1) a department of endocrinology; (2) a department of infectious diseases; (3) a department of pulmonary diseases; (4) a department of gastroenterology; (5) a general medical department; and (6) an ED. Each chosen department will have between 18-40 beds with similar numbers and proportions of physicians, registered nurses and certified nursing assistants. In all hospitals, the physiotherapy service is centrally organised to service all wards.

\section{Qualitative methods}

The qualitative methods will include an ethnographic field study (comprising participant observation and interviews) and workshops to provide in-depth relational knowledge for designing an appropriate patient intervention $^{20}$ and for obtaining knowledge about the contextual circumstances with regard to the implementation, delivery and evaluation of the intervention. These methods, will enable us to account for the context in which events occur and uncover social patterns, for example, which relationships are important for actions related to mobility and for interventions that increase mobility. Qualitative methods are also valuable in exploring the underlying assumptions in relation to the designed intervention and in identifying the so-called active ingredients of a complex intervention ${ }^{18}$ aimed at increasing mobility. Finally, the use of qualitative studies make it possible to determine which groups of participants are most likely to respond positively to the designed intervention, and whether the intervention must be modified in different ways for different groups or departments. ${ }^{20} 2129$ 


\section{Ethnographic field study}

The design phase (figure 1) will begin with an ethnographic field study including participant observation and interviews. ${ }^{29-31}$ Our position will primarily be observant rather than participating. ${ }^{32}$ The field study will enable us to generate rich descriptions of the interactions between health professionals and patients and explore the importance of contextual factors, professional identities and professional boundaries for mobility of older medical patients in the departments. This is crucial since observational knowledge relating to mobility of older medical patients in the departments is sparse. By being physically present in the departments, taking part in and observing the health professionals carrying out their daily activities, we will be able to understand how mobility of older patients is practised in the departments and how it is perceived by different participants. ${ }^{29}$

We have chosen a focused observation strategy, ${ }^{28} 33$ whereby we will follow the health professionals (physiotherapists, nurses, nursing assistants and physicians) in their daily work with a particular focus on language, actions and materialities regarding mobility of patients. We will inquire into what is being done and into arguments for decisions that the health professionals make about mobility in concrete situations. We expect to follow between 60 and 80 health professionals depending on staffing on the days of observation and depending on who is involved in mobility of a given patient.

The observations will be carried out by the researchers, two of whom are trained nurses while two are trained physiotherapists. By choosing researchers with different professional backgrounds, we acknowledge that the ability to gather data and generate knowledge depends on the position of the researcher. ${ }^{32}{ }^{34}$ However, we anticipate that by comparing our observations, we will become aware of our own positions and perspectives and how they frame our observations. Thus, by crosschecking and discussing our observations, we can sharpen our attention on differences of significance for data generation. This process will take place continuously during meetings after each observation period to crosscheck data and interpretations and will strengthen the validity of the results. ${ }^{33} \mathrm{By}$ systematising the observations and creating transparency the observations will ascertain credibility ${ }^{29}$ and enable exploring and understanding of how health professionals make decisions about mobility in interaction with the patients and each other.

We will use an observation guide to record activities and interactions (online supplementary appendix 1). Field notes will consist of observations of both non-verbal and verbal aspects such as body language, dialogue between the health professionals and patients, and the use of material objects such as mobility aids. Dialogues will be written down as close to verbatim as possible. ${ }^{36}$

The observation guide will also include descriptive data (eg, sex, profession and professional experience) and questions like 'Who initiated mobility?', 'Which arguments are raised when patients' needs for mobility are rejected or accepted?', 'Is any kind of materiel artefact used, such as a walker or a screening tool?'. According to Mason ${ }^{37}$ field notes should also include focus areas of 'subjective capabilities'. The intention is that the researcher writes down reflections on his or her own actions, attitudes, location and presence. This increases the understanding of how the researchers affect the relations, underscoring that neutrality and detachment in relation to data collection, analysis and interpretation is impossible.

\section{Analytical perspective}

We will analyse our observational data using different theories: cultural learning processes and cultural historical activity theory. ${ }^{34}{ }^{38}$ These theories can help us understand barriers and transformations in the interaction between the health professionals, structures and objects. Also, it can help us understand how the culture creates ideas about how participants, for example, the nurses, should interpret and act in relation to mobility in the department. $^{34}$

WALK-Cph derives its concept of culture from the theories of cultural learning processes that understand culture not onlyas a homogeneous set of assumptions, attitudes and values that all health professionals possess. ${ }^{36-38}$ Rather, culture is understood as something the health professionals produce in order to create links and connections between materialities and meanings in social and physical spaces. ${ }^{29} 34$ This means that culture does not refer to cognitive processes only, ${ }^{39-41}$ culture is also enacted and has bodily elements embedded. This concept of culture is relevant when we use observational studies, where we can observe how the health professionals act, what they say, what materialities they include and exclude in their professional practice, and how they move in physical spaces. In this perspective, the concept of culture focuses both on what is homogeneous and what is different, for example, between professions. ${ }^{23}$

Data from the ethnographic field study will be analysed using both a thematic analysis and a deductive approach where we will analyse the material from the perspective of different theoretical concepts, for example, as cultural models ${ }^{23}$ and activity systems. ${ }^{38}$

The results from the analysis will be presented and used as mirror data in the subsequent workshop (figure 1). Mirror data are defined as data representing the present state of work practices and these data provide the health professionals with a mirror reflection of their activities by presenting examples of current practice. ${ }^{42}$

\section{The workshops}

After the field study, workshops of 4 hours will be used to develop the WALK-Cph intervention in collaboration with health professionals, patients, relatives and researchers. In the workshops, we will get an opportunity to bring together different forms of evidence-based knowledge, both theoretical and empirical, to accommodate increased mobility of older medical patients. ${ }^{38}$ Furthermore, the workshop method is chosen because 
implementation research points to the importance of involving the persons who are responsible for increasing mobility of older medical patients, in this case the health professionals. ${ }^{26}$ Each workshop will be held in a classroom in the hospital and will be videotaped and audiotaped. The design phase consists of three workshops, which are described below.

\section{Workshop I: health professionals}

Health professionals from the intervention departments and the municipality will participate. The aim of this workshop is to develop a catalogue of initiatives that the health professionals believe will increase mobility of older medical patients. The catalogue will be based on the health professionals' knowledge, experience and attitudes as well as the observational data from the field study. The proposed initiatives will form the basis for the development of the intervention (online supplementary appendix 2).

\section{Workshop II: patients and relatives}

Patients and their relatives will participate. Workshop II has two aims: first, to generate a catalogue of initiatives that the patients and the relatives believe will increase mobility, based on their knowledge, experience, attitudes and mirror data. Second, to obtain feedback from the patients and their relatives on the catalogue of initiatives suggested by the health professionals at workshop I. The initiatives suggested by patients and relatives also contribute to the development of the intervention. The results from workshop II are weighted as much as the results from workshop I.

\section{Workshop III: health professionals}

Health professionals will participate and be introduced to the patients' and the relatives' proposals. The particular aim of workshop III is to finalise a prototype of the intervention. Hereafter, a study focusing on facilitators and barriers (barrier screening) will be performed and the intervention will be adjusted according to the results of the barrier screening and afterwards be tested in a fidelity study (Study II a, figure 1).

Following the design phase, an additional workshop will be conducted.

\section{Workshop IV: health professionals, patients and relatives}

Health professionals, patients and relatives will participate to provide feedback on the proposed intervention. The aim of workshop IV will be to adapt and design the final intervention which will be tested in the fidelity study (Study 3a, figure 1) and subsequently in the Randomised controlled trial (RCT) study.

Between the different workshops, the research team will work systematically to develop the intervention based on the five-phase model for design of interventions: (1) problem analysis and project planning, (2) information gathering and synthesis, (3) design, (4) pilot testing and (5) evaluation. ${ }^{43}$ As a part of the workshops and the barrier screening, inputs from health professionals, patients and relatives will be collected and the research team will score the feasibility of all incoming inputs based on a number of criteria: rationality, complexity, compliance with rules and regulation, required time, economical neutrality, accessibility of equipment and amelioration of patient life quality. Inspired by the Delphi method ${ }^{44}$ all inputs will be scored between 1 and 5 , where 1 represents low complexity and 5 represents high complexity. For example: if the intervention proposal is less complex, the score will be 1 to indicate low complexity. All interventions that have a median score equal to or below 2 will be included in the final intervention.

\section{The participants}

The participants in workshops II and IV will be $8-10$ older medical patients (+65 years) who have been admitted to a medical department and 8-10 relatives who have had a relative, friend or family member ( +65 years) admitted to a medical department. Further, the participants in workshop I, III and IV will be physicians, nurses and nursing assistants, physiotherapists, occupational therapists and managers affiliated with the two intervention departments and the municipalities. The health professionals will be selected by their managers and will be selected both by profession and experience in the medical or physiotherapy department, and for being responsible for the implementation of the intervention. The selection will range from enthusiastic people who are good at initiating and managing interventions, even beyond their own department, to those who have a strong voice within the department and finally, those with the greatest resistance towards the intervention. ${ }^{45}$ This complexity of participants ensures a multivoiceness perspective ${ }^{42}$ on both possibilities and barriers in relation to designing an intervention that has the ability to match the local context.

\section{Barrier screening}

A barrier screening designed as semistructured individual interviews with health professionals will be carried out in the two intervention departments, the physiotherapy departments and the municipalities after the intervention has been designed. The aim of the barrier screening is to explore and understand the health professionals' perceived barriers and facilitators regarding the intervention, once it has been designed (figure 1). The barrier screening will complement the field studies at the organisational level and the workshops at the group level. To ensure that the intervention is based on opinions, attitudes and perspectives from health professionals with positions other than those who participate in the workshops, 20 interviews with health professionals will be conducted. Both contradictory and complementary views are relevant for identifying patterns in the participants' understanding, practices and how they relate to situations involving mobility of older medical patients.

The barrier screening will be designed and analysed based on the Theoretical Domain Framework (TDF) ${ }^{46} 47$ 
and Rogers' framework of innovation attributes. ${ }^{45}$ The purpose of TDF is to identify determinants at an individual level. Rogers' innovation attributes concern a number of perceived characteristics of innovations, which influence their adoption and use. Interventions that do not meet these criteria tend to be difficult to disseminate and implement. ${ }^{48}$

\section{Ethics and dissemination}

Before undertaking observations, interviews and workshops all participants will be informed about the aim of the study. They will be assured that participation is voluntary and that results will be anonymous. All participants will be asked to provide their written, voluntary and informed consent before participation in the workshops and interviews. Anonymity will be ascertained by assigning each participant with a code in the field notes and interviews. Only persons who are part of the research team will have access to data. The project will adhere to the directives of the Helsinki Declaration. ${ }^{48}$ Ethical approval was not required for the study since formal ethical approval is not mandatory for studies that do not involve biomedical issues (I-Suite no: 05078) according to Danish law.

After completing the study, the results will be disseminated to all the health professionals, managers, patients and relatives. They will be invited to afternoon meetings where the findings, the process and cooperation will be in focus. The results from the study will be published in peer-reviewed scientific journals and presented at one or more scientific conferences.

\section{Author affiliations}

${ }^{1}$ Clinical Research Centre, Copenhagen University Hospital Hvidovre, Hvidovre, Denmark

${ }^{2}$ Department of Exercise and Health, Roskilde Municipality, Roskilde, Denmark ${ }^{3}$ Department of Health andSocial Context, National Institute of Public Health, University of Southern Denmark, Copenhagen, Denmark

${ }^{4}$ Clinical Research Centre, Physical Medicine \& Rehabilitation Research-

Copenhagen (PMR-C), Hvidovre, Denmark

${ }^{5}$ Department of Physical and Occupational Therapy, Copenhagen University Hospital Hvidovre, Hvidovre, Denmark

${ }^{6}$ Section of Biostatistics, Department of Public Health, University of Copenhagen, Copenhagen, Denmark

${ }^{7}$ Division of Community Medicine, Department of Medical and Health Sciences, Linköping University, Linköping, Sweden

Acknowledgements The authors thank the management staff from the medical departments, the physiotherapy and occupational therapy departments and the municipalities for their commitment to participate in the study and for giving them the opportunity to conduct field studies in their departments.

Contributors JWK led the study and drafted the manuscript in collaboration with ACB, TT-T, PN and MMP. TB, RSH, OA, JP, LKP extensively revised the manuscript. All authors have approved the final manuscript and are willing to take responsibility for appropriate portions of the content.

Funding Velux Foudation (Lauritz William Foundation) grant number [00013449]. Competing interests None declared.

\section{Patient consent Obtained.}

Provenance and peer review Not commissioned; externally peer reviewed.

Open Access This is an Open Access article distributed in accordance with the Creative Commons Attribution Non Commercial (CC BY-NC 4.0) license, which permits others to distribute, remix, adapt, build upon this work non-commercially, and license their derivative works on different terms, provided the original work is properly cited and the use is non-commercial. See: http://creativecommons.org/ licenses/by-nc/4.0/

(C) Article author(s) (or their employer(s) unless otherwise stated in the text of the article) 2018. All rights reserved. No commercial use is permitted unless otherwise expressly granted.

\section{REFERENCES}

1. Dock W. The evil sequelae of complete bed rest. J Am Med Assoc 1944;125:1083-5.

2. Brown CJ, Williams BR, Woodby LL, et al. Barriers to mobility during hospitalization from the perspectives of older patients and their nurses and physicians. J Hosp Med 2007;2:305-13.

3. Zisberg A, Shadmi E, Sinoff G, et al. Low mobility during hospitalization and functional decline in older adults: In-hospital mobility levels and functional decliNE. J Am Geriatr Soc 2011:59:266-73.

4. Brown CJ, Friedkin RJ, Inouye SK. Prevalence and outcomes of low mobility in hospitalized older patients. J Am Geriatr Soc 2004:52:1263-70.

5. Henneman PL, Fisher DL, Henneman EA, et al. Patient identification errors are common in a simulated setting. Ann Emerg Med 2010;55:503-9.

6. Danmark S. Styrket indsats for den ældre medicinske patient: fagligt oplæg til en national handlingsplan. Sundhedsstyrelsen. Denmark: The Danish Health Authority, 2011. Strengthened efforts for the older medical patient - a proposal for a national action plan.

7. Pedersen MM, Bodilsen AC, Petersen J, et al. Twenty-four-hour mobility during acute hospitalization in older medical patients. $J$ Gerontol A Biol Sci Med Sci 2013;68:331-7.

8. Brown CJ, Roth DL, Peel C, et al. Predictors of regaining ambulatory ability during hospitalization. J Hosp Med 2006;1:277-84.

9. Boyd CM, Landefeld CS, Counsell SR, et al. Recovery of Activities of Daily Living in Older Adults After Hospitalization for Acute Medical Illness: functional recovery after hospitalization. J Am Geriatr Soc 2008:56:2171-9.

10. Boyd CM, Xue QL, Guralnik JM, et al. Hospitalization and development of dependence in activities of daily living in a cohort of disabled older women: the Women's Health and Aging Study I. J Gerontol A Biol Sci Med Sci 2005;60:888-93.

11. Callen BL, Mahoney JE, Grieves CB, et al. Frequency of hallway ambulation by hospitalized older adults on medical units of an academic hospital. Geriatr Nurs 2004;25:212-7.

12. Doherty-King B, Yoon JY, Pecanac K, et al. Frequency and Duration of Nursing Care Related to Older Patient Mobility: Nursing Care Related to Mobility. J Nurs Scholarsh 2014;46:20-7.

13. Brown CJ, Flood KL. Mobility limitation in the older patient: a clinical review. JAMA 2013;310:1168.

14. Nilsen P, Bernhardsson S. Towards evidence-based physiotherapy research challenges and needs. J Physiother 2013;59:143-4.

15. Dishman RK, Sallis JF, Orenstein DR. The determinants of physical activity and exercise. Public Health Rep 1985;100:158-71.

16. Kirk W, Nilsen P. Implementing evidence-based practices in an emergency department: Contradictions exposed when prioritizing a flow culture. J Clin Nurs Accept 2015.

17. Kirk JW, Nilsen P. Implementing evidence-based practices in an emergency department: contradictions exposed when prioritising a flow culture. J Clin Nurs 2016;25(3-4):555-65.

18. Baker R, Camosso-Stefinovic J, Gillies C, et al. Tailored interventions to overcome identified barriers to change: effects on professional practice and health care outcomes. In:The Cochrane Collaboration. Cochrane Database of Systematic Reviews. Chichester, UK: John Wiley \& Sons, Ltd.

19. Carman KL, Dardess P, Maurer M, et al. Patient and family engagement: a framework for understanding the elements and developing interventions and policies. Health Aff 2013;32:223-31.

20. Jansen YJ, Foets MM, de Bont AA. The contribution of qualitative research to the development of tailor-made community-based interventions in primary care: a review. Eur $J$ Public Health 2010;20:220-6.

21. MRC. A framework for the development and evaluation of RCTs for complex interventions to improve health. Rep No 200018 Lond Med Res Counc. 2000.

22. Bhaskar R. A Realist Theory of Science. Hemel Hempstead: Herts: Harvester Wheatsheaf, 1975.

23. Hasse C. An anthropology of learning: on nested frictions in cultural ecologies. New York: Springer Berlin Heidelberg, 2014. 
24. Archer MS, ed. Critical realism: essential readings. London; New York: Routledge, 1998:756.

25. Satariano WA, Guralnik JM, Jackson RJ, et al. Mobility and aging: new directions for public health action. Am J Public Health 2012;102:1508-15.

26. Fixsen DL, Naoom SF, Blase KA, et al. Implementation research: A synthesis of the literature, 2005. http://centerforchildwelfare2.fmhi. usf.edu/kb/Implementation/Implementation\%20Research\%20-\% 20A\%20Synthesis\%20of\%20Literature\%20\%20-\%202005.pdf (cited 1 Feb 2014).

27. Curran GM, Bauer M, Mittman B, et al. Effectiveness-implementation hybrid designs: combining elements of clinical effectiveness and implementation research to enhance public health impact. Med Care 2012;50:217-26.

28. Wolcott HF. Confession of a "trained" observer. In:Description, Analysis and Interpretation. Thousands Oaks: Sage Publications, 1994.

29. Hastrup K, Rubow C. Kulturanalyse. Kort fortalt. Frederiksberg C, København: Samfundslitteratur, 2011.

30. Hastrup K. Ind i verden: en grundbog $i$ antropologisk metode Kbh: Hans Reitzel, 2003.

31. Spradley JP. The Ethnographic Interview. London: Holt, Rinehart \& Winston, 1979. http://www.statsbiblioteket.dk/au/index.jsp?query= Spradley+J.P.+\%281979\%29+The+Ethnographic+Interview.+Holt\% $2 \mathrm{C}+$ Rinehart+\%26+Winston $\% 2 \mathrm{C}+$ London\&first_search=true\& keepFilter=false\&delimitType=available. (cited 21 Oct 2013)

32. Spradley JP. Participant observation: Waveland, Press Inc, 1980.

33. Tjørnhøj Thomsen T, Reynolds Whyte S. Fieldwork and partipant observation. Research methods in public health: Gyldendal Akademisk, 2008.

34. Hasse C. Kulturanalyse i organisationer. Begreber, metoder og forbløffende læreprocesser. Frederiksberg, Samfundslitteratur, 2011. http://www.statsbiblioteket.dk/au/index.jsp?query= Kulturanalyse+l+organisationer.+Begreber\%2C+metoder+og+ forbl\%C3\%B8ffende+l\%C3\%A6reprocesser\&first_search=true\&
keepFilter=false\&delimitType=\#/?recordld=sb_5228224. (cited 21 Oct 2013).

35. Hastrup K. Getting it right: Knowledge and evidence in anthropology Anthropol Theory 2004:4:455-72.

36. Berg BL. Qualitative Research Methods for the Social Sciences. 3rd edn. Boston: MA:Allyn and Bacon, 1998.

37. Mason J. Qualitative Researching. London: Sage, 1996.

38. Learning-by-Expanding EY. An Activity-Theoretical Approach To Developmental Research. Helsinki: Orienta-Konsultit, 1987.

39. Weick KE. Organizational culture as a source of high reliability: National Emergency Training Center, 1987. http://www.aml-safety. com.au/AMLstores/_images/pdf-files/Weick1987.pdf. (cited 17 Dec 2015).

40. Schein EH. Process consultation: its role in organization development. Reading, Mass.: Addison-Wesley, 1969.

41. Schein EH. The role of the founder in creating organizational culture. Organ Dyn 1983;12:13-28.

42. Kerosuo $\mathrm{H}$, Engeström $\mathrm{Y}$, Kajamaa A. Promoting innovation and learning through Change Laboratory: An example from Finnish health care. Cent Eur J Public Policy 2010;1:110-31.

43. Rothman J, Edwin JT. Intervention research: design and development for human services. New York: Haworth Pres, 1994.

44. Linstone HA, Turoff M. The Delphi Method. Tech Appl. 53, 2002. ht tps://pdfs.semanticscholar.org/8634/72a67f5bdc67e4782306efd883 fca23e3a3d.pdf. (cited 17 Sep 2017).

45. Rogers EM. Diffusion of innovations. New York; London: Free Press; Collier Macmillan, 1983.

46. Michie S, Johnston M, Abraham C, et al. Making psychological theory useful for implementing evidence based practice: a consensus approach. Qual Saf Health Care 2005;14:26-33.

47. Cane J, O'Connor D, Michie S. Validation of the theoretical domains framework for use in behaviour change and implementation research. Implement Sci 2012;7:37.

48. Code N. The Nuremberg Code. Trials War Crim Nuremberg Mil Trib Control Counc Law, 1949;10:181-2. 